\title{
The limits of process: on (re)reading Henri Bergson
}

\author{
Abstract \\ This article offers a reading of the work of Henri Bergson as it pertains to organizations through the \\ lens of ideas drawn from critical realism. It suggests an alternative to interpretations based on a \\ stark division between process and realist perspectives. Much of the existing literature presents a \\ rather partial view of Bergson's work. A review suggests some interesting parallels with themes in \\ critical realism, notably the emergence of mind. Critical realism has a focus on process at its heart, \\ but is also concerned with how the products of such processes become stabilized and form the \\ conditions for action. This suggests that attention might usefully be paid to the relationship between \\ organizational action and the sedimented practices grouped under the heading of 'routines'. More \\ attention to Bergson's account of the relationship between instinct, intuition and intelligence \\ provides a link to the social character of thought, something which can be mapped on to Archer's \\ work on reflexivity and the 'internal conversation'. This suggests that our analyses need to pay \\ attention to both memory and history, to building and dwelling, rather than the one-sided focus \\ found in some process theory accounts.
}

\section{Keywords}

Critical realism, process, emergence, relational sociology, Archer

\section{Acknowledgements}

My thanks to Paulo Morgado for stimulating discussions about Bergson; this interpretation, of course, remains my responsibility. Thanks also to participants in the EGOS standing working group on history over the years, especially to John Connolly for pushing the case for Elias. 
The work of the French philosopher Henri Bergson, active at the beginning of the twentieth century, has been an important influence on 'strong' process perspectives on organizations and organizing. Used to advocate an ontology of 'becoming' in which reality is in a state of permanent flux and movement, these ideas have found crystallisation in an important Handbook (Helin et al 2014), as well as being used to support alternative conceptions of strategy (Chia and Holt, 2009). In turn, they have been influential in areas such as the study of organizational routines, giving weight to tendencies to stress the dynamic potential of such routines for fostering organizational change (Pentland et al, 2012). While Bergson is only one of many thinkers whose work has been invoked in the support of a strong process perspective, he offers the opportunity for a reassessment of such approaches. This article conducts such a reassessment through the lens of critical realism. Now, it might be expected that such a reassessment would involve the counter-posing of conceptions of structure to the focus on flows in processual thinking. That is indeed part of the story, but only part of it. What an examination of Bergson indicates is not only that there is more to his work than existing accounts would indicate but, just as important, that critical realism is just as concerned with process and movement as with order and stability. Not only does such an examination suggest some limits to process, but it also points to areas for the refinement of the critical realist project in organization studies.

The article starts by considering how Bergson's work has been used. One observation from this discussion is that supplied by Weik (2011), who observes that the polarized nature of the discussion means that alternatives to stylized and stereotyped positions are not considered. This provides a reason for considering the relationship between Bergson, process and critical realism. It is recognised that there is little direct consideration but that addressing the questions raised by process theorists enables us to pull out some of the focus on process in critical realist approaches. This leads to a focus on some specific elements of Bergson's thought, notably questions of emergence in the context of the mind-brain relationship and the nature of the distinction between instinct, intuition and intelligence. I use examples drawn from the study of organizational routines to 
illustrate the interplay between instinct, as situated action, and intelligence, as generalizing from such action and sedimenting learning in specific practices. This discussion both suggests some limits to the focus on flows in strong process thinking and the need for those in the critical realist tradition of organizational analysis to take practices more seriously.

\section{Uses of Bergson}

It is worth noting that many mentions of Bergson in the journal literature are made in passing, as either a marker of a broad adherence to a processual perspective or as support for a wider more conventional argument about organizational change. ${ }^{1}$ This often done without direct reference to Bergson's work. In addition, there is a small subset of articles which use Bergson's work on humour to examine that specific topic (Westwood, 2004; Korczynski, 2011). As a specialised area of endeavour, they will not be considered in detail here. If we set these articles aside, then in the remainder it is noticeable how often Bergson's ideas are mediated through the work of other thinkers (Linstead, 2014: 230). Of particular prominence here is the work of Deleuze, either alone or in tandem with Guattari. At least five articles have Deleuze as their major focus, with recognition of his re-working of Bergsonian ideas (Wood and Ferlie, 2003; Thanem, 2006; Linstead and Thanem, 2007; Hjorth and Pelzer, 2007; Painter-Morland and Deslandes, 2014). Other thinkers cited where Bergson is seen as an influence are Whitehead, Sartre, Weick and Mead (Cunliffe and Luhman, 2004; Simpson, 2009; Bakken and Hennes, 2006; Weber and Glynn, 2006). The influence on American pragmatism is brought out in Wood and Ferlie (2003: 54) who claim to couple the 'phenomenological intuitionism of Bergson (1912) and the radical empiricism of James' in their analysis. This connection with the work of William James is one to which we will return. What one also notes is that the use of Bergson is often restricted to a rather narrow range of his work, with

\footnotetext{
${ }^{1}$ The claims made in this section are based on articles which mention Bergson in either Organization Studies or Organization from 1993 to 2014. This does not purport to be an exhaustive, systematic, bibliographical analysis, but rather to focus on the literature where the main contributions have occurred. The focus on European journals reflects, as Meyer and Boxenbaum (2010) note, that references to Bergson tend to reflect a particularly European style of research. The discussion is supplemented with other material, but is not claimed to be comprehensive.
} 
only a handful of articles making reference to several of his works. In a population of 35 articles in which Bergson's name appears, 12 make no direct reference to his work. The biggest, number, 16, use only one source, with the most frequently used work being Creative Evolution. This points to the serious and direct engagement with his work being limited to a handful of authors, most notable amongst whom is Robert Chia $(1997,1998)$. Because of this, the focus of the following discussion is on his work, complemented by that of Stephen Linstead (2014) and Ajit Nayak (2008), as authors who have engaged most comprehensively with Bergson's work.

It is Chia who most clearly expresses the fundamental point which Bergson is recruited to support: the ontological notion that what we term reality is in a state of permanent becoming. As he puts it:

The actual world is fundamentally in a process of becoming so that every phenomena of which we are aware - from galaxies to electrons, from human beings to amoebae, from human societies and families of crystals to nursery rhymes and creational myths - each exist only as a stabilized moment in an interminable process of becoming (Chia, 1997: 696).

The consequence is that the object of our study is regarded as a by-product of the process of becoming. 'Individuals, organizations and societies,' argue Nayak and Chia, 'are deemed to be epiphenomena of primarily fluxing and changing patterns of relationships and event clusterings (Chia and Nayak, 2011: 283).This discussion is based on an example that Bergson uses to illustrate the problem of movement. First, we have to recognise a key distinction, that between intelligence and instinct. The former is 'is characterized by the unlimited power of decomposing according to any law and of recomposing into any system' (Bergson, 1960: 165). Thus, when looking at the movement of an arm, intelligence, in the form of analytical science, breaks it down into a series of discrete points which can be mapped in space. However, no matter how sophisticated the measurement and how close together the points, this can never capture the movement itself. For this reason, argues Bergson, 'The intellect is characterized by a natural inability to comprehend life' (Bergson, 1960: 
174). A true comprehension of movement and thus of evolution rested on intuition, a lived sympathy with the flow of consciousness. As he argued

To get a notion of this irreducibility and irreversibility, we must break with scientific habits which are adapted to the fundamental requirements of thought, we must do violence to the mind, go counter to the natural bent of the intellect. But that is just the function of philosophy (Bergson, 1960: 31).

He was particularly concerned to resist the claims of 'psychophysics', that is the attempt to combine the growing prestige of physics with the rapid development of the discipline of psychology at the closing years of the nineteenth century (Bergson, 1910: 61). For him, any attempt to measure consciousness was invalid, for it was to mistake the homogeneous nature of points in space, where any one point could be exchanged with another, with what he termed the 'qualitative multiplicity' of consciousness (Bergson, 1910: 122).

This led him to the notion of 'duration'. Pure duration was the property of consciousness in 'the flow is continuous and in which we pass insensibly from one state to another: a continuity which is really lived, but artificially decomposed for the greater convenience of customary knowledge' (Bergson, 2007: 243). This duration was sustained by memory, which retained and developed the sense of self. Memory operated at two levels: motor mechanisms and independent recollections (Bergson, 2007: 87). Because of memory, the past was ever intruding on the present. As he argued

What are we, in fact, what is our character, if not the condensation of the history that we have lived from our birth - nay, even before our birth, since we bring with us prenatal dispositions? Doubtless we think with only a small part of our past, but it is with our entire past, including the original bent of our soul, that we desire, will and act. Our past, then, as a whole, is made manifest to us in its impulse; it is felt in the form of tendency, although a small part of it only is known in the form of idea (Bergson, 1960: 5). 
The problem comes with how to know this world. Here, the resources and achievements of science are misleading. They have 'led to a falsely held view of reality in which the prevailing assumption remains that movement and change are epiphenomenal aspects of an essentially stable reality that can be systematically investigated and unproblematically represented through the established symbolic codes of modern science' (Chia, 1998: 356). Wood and Ferlie (2003: 54) put this most starkly when they stress 'the alinear, multiple and the heterogeneous over the linear, predicatable and homogeneous and in which primacy is placed on process, transformation and flux: the becoming of things over the realist primacy on substance, stability, and order'. The adequacy of these stark distinctions is a matter to which we will return, but much of the discussion of Bergson is related to epistemological concerns once a world in flux is accepted.

This is why a good deal of the focus is on intuition as a method. For Nayak (2008: 173), 'intuition, in the Bergsonian sense, is a precise method to deepen and enhance our understanding of reality as movement.' In what does this method consist? Firstly it involves, according to Nayak 'strenuous effort' in order 'to think against our habitual grain of thought'. This means that 'Intuition as a method is not easy to understand. The task of intuition is to 'think beyond' by gaining 'intellectual sympathy' with lived experience that is movement' (Nayak, 2008: 180, 181). But how is this to be done? The first move is to focus on defining problems rather than uncovering them. 'Thus,' Nayak (2008: 182) argues, 'the first step in the method of intuition is to 'invent' true problems.' Having done this, then how are we to investigate such problems? Why, we are 'to reveal the experience of duration' (Nayak, 2008: 182). And how is this to be done - by thought. 'I emphasize,' argues Nayak (2008: 187), ' a way towards organizing thought rather than specific end-points, hypotheses or findings'. I have laboured this point a little, for the 'precise method' proves, at least in the hands of Nayak, to be anything but. We end up with suggestions about ways of thinking, ways which are taken up, too, in Shotter's argument. In his clearly labelled 'Understanding Process From Within: An Argument for 'Withness' Thinking, he suggests that this mode of thinking means 
of thinking about changes in a living, indivisible state of affairs from the outside in terms of them going through a sequence of separate immobile spatial configurations, we can begin to think in accord with their changing nature from within our living relations with them. For, if we can allow ourselves to be spontaneously responsive to the temporal unfolding of their expressive movements, then we can, of course, find that same unfolding movement within our own bodily felt experience (Shotter, 2006: 586).

It is such injunctions that lead Weik (2011) to suggest that there is a tendency toward solipsism, in which we are obliged to trust to the introspection of the analyst to obtain insights into the modes of becoming of others and of wider phenomena, such as organizations. There is an inherent problem, here, for Bergson himself stressed both the difficulty and rareness of such introspection. 'The moments at which we thus grasp ourselves are rare', he argues (Bergson, 1910: 20). Interestingly he suggests that, subject to the problems of language, which render static something which is in motion, that it is artists who offer insights. A novelist, for example, might make 'us reflect by giving outward expression to something of that contradiction, that interpenetration, which is the very essence of the elements expressed. Encouraged by him, we have put aside for an instant the veil which we interposed between our consciousness and ourselves' (Bergson, 1910: 133). Chia (1998: 359), too, argues that 'the clearest form of penetrating intuition comes to us from the work of great artists'. Chia and Holt (2009: 144-150) echo this point, drawing on, for example, the paintings of J. M. W. Turner and Gothic architecture. (Examples of work which seek to develop this position are Beyes and Steyaert (2011) and Borch (2009)). This is a point to which I will return below.

However, before doing so I also need to stress is the extent to which Bergson was concerned with the problems of consciousness, which he related to deep inner feelings.

The greater part of the time we live outside ourselves, hardly perceiving anything of ourselves but our own ghost, a colourless shadow which pure duration projects into homogeneous space. Hence our life unfolds in space rather than in time; we live for the 
external world rather than for ourselves; we speak rather than think; we "are acted" rather than act ourselves (Bergson, 1910: 231).

It is this world of deep feelings, the 'real' self buried deep within each individual, rather than the shadow world of the social with which he was primarily concerned. While one recognises a more social dimension in his work on humour, in the organizational literature, as we have seen, this is bracketed off as a very specific contribution. What is noticeable in the process discussions is the way in which discussion slips from Bergson's focus on consciousness into a consideration of the social. For example, in Wood and Ferlie's (2003: 64) discussion of evidence-based healthcare there is the following statement: 'clinical services and research information 'melt into and permeate one another, without precise outlines' (Bergson 1910: 104).' The citation from Bergson is from Time and Free Will in a discussion of consciousness and duration, in which he argues that 'pure duration might well be nothing but a succession of qualitative changes, which melt into and permeate one another, without precise outlines, without any tendency to externalize themselves in relation to one another, without any affiliation with number: it would be pure heterogeneity' (Bergson, 1910: 104) That is an argument about deep consciousness, as outlined above, not about the social. To argue that aspects of the social have blurred boundaries seems legitimate; it might be thought, however, that it is not so legitimate to slip so easily from the psychological to the social. However, this is what we find when the work of Bergson is advocated as a model for organizational analysis. Thus Calori (2002: 137) moves from observing Bergson's comment on the limitations of deduction 'in the psychological and moral sciences' to a 'hence, in organization studies'. This slippage between a discussion which, in Bergson's hands, is illuminating about matters of psychology to one which makes claims about the social world is to be seen starkly in Chia's discussion when he moves from his outline of Bergson's ontology of becoming, derived from his discussion of consciousness, to an argument that we need to move to analyses of organizing as 'a generic reality-structuring feature of modernity' (Chia, 1998: 363). Here he cites as exemplars the work of Weber, Foucault and Elias. Now, given what we know about Weber's dismissal of psychology except as it applied to exceptional cases, this seems an 
unwarranted jump (Ghosh, 2008: 254). This is not to say that Weber was 'right', but simply to point to the elision of the psychological and the social in the hands of strong process theorists.

What also seems apparent from their work is an almost Manichean division between 'science' and its other, the other in this case being process perspectives. This is seen most clearly in Chia's (1998: 356) phrase about 'the entire attitude of modern science'. On this count, science tout court 'revolves around the axis of centred thinking which itself is predicated upon the prior spatializing and quantification of natural and social phenomena' (Chia, 1998: 356). Setting aside the debates within physics sparked by the mysteries of quantum mechanics, as explored, for example, by Barad (2007; see also Norris (2000)), this seems to be an altogether too sweeping characterisation of aspects of science such as biology. We will consider this further below, but this extreme polarisation, Weik (2011) persuasively suggests, means that approaches which do not share the scienticism that Chia and others seem to have in mind, one associated with physics, mathematics and aspects of some disciplines, such as economics, one which seeks to reduce reality to symbolic quantification, are overlooked. Thus Hernes and Bakken (2003: 1524) note that in only contrasting two possibilities Chia 'excludes the possibility of recursivity, which in many ways tries to avoid the structure-process opposition.' The same authors argue, on a similar basis, for further consideration of Whitehead's work (Bakken and Hennes, 2006). Another approach, one which I will argue also takes process seriously, is that of critical realism, and it is to a reading of Bergson informed by critical realism that I turn next.

Some preliminary comments on Bergson's oeuvre are in order before considering some aspects of it in conjunction with critical realism. An excellent introduction to his life and intellectual biography is supplied by Linstead (2014), so this overview is concerned with some broad observations. One is the degree to which Bergson was engaged by some of the scientific controversies and debates of his day. This gives the lie to any idea that he dismissed the gains of science. In his consideration of Matter 
and Memory, for example, he engaged with contemporary work on the brain; in Time and Free Will he refers to draws on, amongst others, "Professor William James [who] drew the attention of physiologists to certain phenomena which had been but little remarked, although they were very remarkable' (Bergson, 1910: 22). This perhaps gives a slightly dated feel to some of his work, given that much of this material has been superseded by the remarkable advances of science during the twentieth century. However, it is the observations which he drew which remain pertinent, as we shall see. The second observation is to cement that made above that Bergson was particularly exercised by the phenomenon of consciousness. As Schatzki (2006: 1867) notes, there is some doubt about the advisability of extrapolating consciousness at the level of individuals to that at the level of groups. This needs to be borne in mind when we consider the applicability or otherwise of Bergson's ideas to the social world.

\section{Critical realism}

What follows is necessarily selective in its treatment of both Bergson and critical realism. In the case of the latter there is a large and growing body of work. This has often seen, by both supporters and detractors alike, as being centrally concerned with structure (Reed, 2005; Contu and Willmott, 2005). That is an important consideration, to be sure, but in what follows I focus on aspects of the approach which stress process, albeit in articulation with structures and in a way which might challenge strong process theorizing. In so doing, however, I wish to start with an observation which supports the focus of both Bergson and Chia on the aesthetic as a means of knowing. The philosopher of science, Hilary Rose (1994: 25), working in the critical realist tradition, observes 'Perhaps truth in the strong sense used by Rorty et al. never exists outside the certainty of 'true forme', which I get when I read a poem or a novel.' That is, while the critical realist project argues that some explanations of the world are better than others, those explanations are always provisional and open to correction. 
Those informed by critical realism have worked in a wide variety of domains. It remains the case that the main intellectual inspiration for the project at a philosophical level, Roy Bhaskar, made only passing and rather dismissive mentions of Bergson. In a 1982 symposium on the interface between social theory and social science he lumps 'Bergsonian intutionism' together with other examples of what he takes to be 'immaterialism' (although it is interesting to note that none of the other distinguished contributors so much as mentions Bergson in a collection with a strong focus on mind) (Bhaskar, 1982: 278). In considering Nietzsche in a work dedicated to Problems of Philosophy and their Resolution, Bergson is brought in to support a contention of Nietzsche's that 'language necessarily falsifies reality in the interests of biological survival' (Bhaskar, 1994: 199). Some of Bhaskar's suspicion may have been generated by Bergson's invocation of élan vital, carrying with it overtones of vitalism. Linstead (2014) associates this with creativity, Brown (2006) with organizing itself, but it is noticeable here that most of those whose work we have been reviewing, with the exception of Calori (2002), do not address this question of the spirit animating human life, perhaps with good cause. Will was the driving force of evolution, argued Bergson:

So that all life, animal and vegetable, seems in its essence like an effort to accumulate energy and then let it flow into flexible channels, changeable in shape, at the end of which it will accomplish infinitely varied kinds of work. That is what the vital impetus, passing through matter, would fain do all at once (Bergson, 1960: 267).

Since those words, of course, science has moved on, most notably with the discovery of DNA. The danger here, of course, is with forms of genetic determinism which threaten to reduce human consciousness to the interplay of genetic material. The counter to this, however, is not the positing of some mysterious spirit but the recognition of emergence as a counter to reductionism. We can see this in critical realism in the work of lan Moll on the interface between psychology and biology. Here, Moll uses Bergson, alongside Spinoza and Marx, as part of his argument 'that mind is an emergent property of brain rather than identical with it' (Moll, 2004: 51). It is clear, as Linstead 
(2014: 223) points out, that Bergson is sharply opposed to any conception which reduces thought and consciousness to the material functioning of the brain. As Bergson put it while 'the intensity of a sensation bears witness to a more or less considerable work accomplished in our organism; but it is the sensation which is given to us in consciousness, and not this mechanical work' (Bergson, 1910: 67). Reviewing work on damage to the brain, he recognised that bodily activity was necessary but that science had indicated that in none of such cases 'do we find memories localized in certain cells of the cerebral substance and abolished by their destruction' (Bergson, 2007: 153). This is a prescient observation which advances in the science of the brain confirm, but which is helped not by regarding mind and memory as some sort of free floating 'elan vital', but as an emergent property. Understanding this requires a brief consideration of two important concepts in the critical realist canon, stratification and emergence.

For critical realists there are two senses in which reality is stratified (Sayer, 1992). A distinction is made between the empirical, the actual and the real, the real being the mechanisms that produce the states of the matter that we investigate. There is a second sense which is important here, and which is shared with other non-reductionist perspectives. This is that we can see reality as consisting of levels, each of which has mechanisms and properties proper to that level but out of which are produced phenomena which cannot, once emergent, be reduced to those mechanisms and properties. Thus, matter emerges from certain physical properties at the level of particles that combine to produce properties which are chemical in nature. Certain arrangements at this level produce biological organisms which possess properties which cannot be dissolved into their constituent parts without losing what it is that makes them effective organisms. From such biological material, in the case of human organisms, emerge psychological and, argue critical realists, social properties. In this particular case, the biological material we are concerned with is the brain, out of which emerges mind. Scientists such as Damasio (1994) and Rose (1993) have shown how even when regions of the brain which are specialized to specific tasks are damaged, that the mind is capable of reorganizing itself to preserve functioning. Rose, in particular, draws on critical realism to 
argue for the emergent properties of mind, what Archer would term, as we will see below, a 'personal emergent property'. This then provides an alternative to any notion of vitalism. Consciousness is not some sort of free floating universal spirit, but an emergent property of particular arrangements that constitute a specific organism, arrangements that emerge from but are not reducible to material properties. This is one way in which Bergsonian insights can be maintained without adhering to a strong view of process. However, this is to remain at the level of the individual organism. Ideas drawn from critical realism both develop Bergsonian ideas of consciousness and, crucially, give them a social dimension.

This social dimension is supplied by the work of Margaret Archer. Two preliminary observations are in order. The first is that Archer is best known for her work on the relationship between structure and agency (Archer, 1995). In her discussion of morphogenesis, structures such as markets and religions are the product of human activity, but, once emergent from that activity, endure to provide the objectives circumstances in which subsequent rounds of that activity takes place. However, her work has been concerned to suggest that the relationship between agency and structure is mediated by agential reflexivity, though the mechanism of the internal conversation (Archer, 2000, 2003). This leads to the second observation, that in developing these ideas she in no place draws on Bergson. However, a crucial part of the development is a close engagement with the work of William James, especially his observations on the nature of consciousness and the possibilities of access to it. As we noted above, Bergson and James shared similar approaches and concerns. It seems legitimate, therefore, to explore Archer's discussion, not least because it throws new light onto the use of Bergson's ideas.

Archer's (2003) use of James is only a small part of her development of the notion of the 'internal conversation', something she suggests James hinted at but which was lost in the later work of the American pragmatists. She outlines, and endorses, James' account of the inherently interior and subjective nature of thought. James is, she argues 'perfectly clear about the distinction between 
abstract ideas and particular thoughts; the former belong to the public domain whilst the latter are intrinsically private' (Archer, 2003: 58). Although Archer never draws on Bergson, we can see striking parallels here. Where, however, her account departs from some of those we have reviewed above is in discounting the possibility of introspection for grasping these thoughts. As she notes "James steadily elaborates the incompatibilities between his conception of the 'stream of consciousness', of thought streaming over time, and the fundamental introspective notion of being able to 'look at it" (Archer, 2003: 60). This is for two reasons. One is that many thoughts are fleeting and inchoate, unable to be inspected before they have vanished. More importantly, simultaneously producing thoughts and inspecting them implies a split consciousness, able to act as subject and object simultaneously. One solution to this problem is then not introspection but retrospection, in which the best we can hope for is reporting of thoughts after they have occurred. However, as Archer notes, 'The life of the mind is fundamentally Heraclitan, for it never descends twice into the same stream' (Archer, 2003: 60). This makes accurate retrieval of memories for inspection an impossibility. In many ways this critique mirrors those which draw on Bergson to challenge 'ocularcentrism', or the primacy of the visual in knowing the world (Kavanagh, 2004). However, it is noticeable that the injunctions from 'strong' process theorists, such as Nayak (2008), cling to the centrality of introspection.

In this sense, Archer's discussion is more faithful to the qualities of thought that both Bergson and James map out. Her suggestion is that James supplied some clues about an alternative monitoring of thought, one which involved talking and listening, rather than sight. She uses this to develop her notion of the internal conversation. This is not the place to explore these rich ideas in more detail, save to note two important points. One is that this account is explicitly characterised as a 'processural and tendential account of thinking' (Archer, 2003: 99). The second is that this account of the interior life of thought is connected to the social. This is where her earlier work on the ways in which enduring structures and cultures form situational logics for action forms a crucial context for her account of thought. Her own summary expresses this best: 
(i) Structural and cultural properties objectively shape the situations which agents confront involuntarily, and possess generative powers of constraint and enablement in relation to (ii) Agents' own configuration of concerns, as subjectively defined in relation to the three orders of natural reality - nature, practice and society.

iii) Courses of action are produced through the reflexive deliberations of agents who subjectively determine their practical projects in relation to their objective circumstances (Archer, 2003: 135).

That is, people take action, but not in circumstances of their own choosing. Those circumstances provide direction to action in three areas in which agents find themselves, in their embodied relations to the natural world, their interpersonal relations and their relations to the collective social world. In each case agents need to reflect on their responses to the demands of those areas. These can be demands of a direct kind, like the need for food to sustain activity, or of a rather more indirect but still pressing nature, like the desire to conform to perceived norms. In all cases, agents can choose to do other than what is suggested by the circumstances they find themselves is, to cut against the grain as it were, but they may have to pay a price for so doing.

Now, this is a complex argument, developed at considerable length. From it, I want to develop in particular the stress on practice that Archer (2000) gives us in her account of Being Human. Critical realism is often seen as being concerned with broader structures, but this might be another misreading. For if we turn to the account of the social world given by Roy Bhaskar in his Transformational Model of Social Action we encounter a significant term, one which appealed to Giddens in his development of structuration theory (Stones, 2005). Whereas Archer uses an outline of system-institution-organization-role as key structural components, Bhaskar uses 'positionpractices' as an alternative to roles. This draws our attention to the tight coupling of particular practices to positions. One aspect of such position-practices in organizations is the routine, introduced at the beginning of this discussion. I wish to bring routines in by considering a rather 
neglected aspect of Bergson's work, his distinction between instinct, intuition and intelligence. Two points are of interest here in the discussion of Bergson's work that we considered above. One is that intuition is discussed in terms of access rather than in terms of being a key way in which actors make sense of their world. The second is that this threefold distinction, which is central to Creative Evolution, is missing from the accounts we have considered, with the focus being on a rather dualistic treatment of intuition and intelligence.

Bergson (1960) actually commences his discussion with a contrast between instinct and intelligence. Evolution, he suggests, has branched in these two directions, with humans developing intelligence. Instinct is a reaction to situations, in which knowledge is tightly bound to activity. Two factors shape the evolution away from instinct in humans. One is embodied mobility, which puts humans in a variety of situations, the unfamiliarity of which challenges any instinctive response. The second is language, which means that such a variety of responses can be conceptualised. However, it is important that while the intelligence that is developed is distinctive, with its primary characteristic being thought as opposed to the activity of instinct, 'all concrete instinct is mingled with intelligence, as all real intelligence is penetrated by instinct' (Bergson, 1960: 143). However, intelligence possesses the key advantage of being mobile, while instinctive knowledge, although deeper and richer, remains tightly bound to its object.

What, then, of intuition, which has formed such an important part of strong process theorizing? 'By intuition', says Bergson, 'I mean instinct that has become disinterested, self-conscious, capable of reflecting upon its object and of enlarging it indefinitely' (Bergson, 1960: 186). This formulation suggests the dangers of a strong separation between intelligence and intuition, with intelligence being further restricted to particular forms of science. However, it does remain the case that, having set up this relationship between intuition and the intellect, he then challenges it. The intellect, he argues, being centred on practical challenges, carves up the world and renders it static. To counter this there needs to be a turn to intuition and the experience of real duration. Here he is faced with a 
challenge, because how are we to know that world, other than through intelligence? After all, his arguments are couched in the very language that is inadequate to the task. (A problem echoed by Linstead when he observes that some accounts (e.g. Chia (1998) and Tsoukas and Chia (2002)) which draw on Bergson are themselves highly intellectual in character (Linstead, 2014: 227)). Bergson's answer is knowing through action. "In theory,' he confesses, 'there is a kind of absurdity in trying to know otherwise than by intelligence; but if the risk be frankly accepted, action will perhaps cut the knot that reasoning has tied and will not unloose' (Bergson, 1960: 203). His analogy here is with swimming, which we learn, he suggests by doing, not by the analogy with walking. However, it could be objected that this analogy only works in so far as it rests at the common sense level of practical coping. If we move, for example, into the world of competitive swimming, then swimmers have to unlearn the strokes they have instinctively developed, based on the input of intelligence. One can see how strong process theorists have focused on intuition, flow and duration, as these are where Bergson leaves us. However, his earlier arguments do tend to suggest a much closer relationship between intuition, as theorised instinct, and intelligence. This is especially the case if we leave the identification of intelligence with science and return to Bergson's observation that 'intelligence, considered in what seems to be its original feature, is the faculty of manufacturing artificial objects, especially tools to make tools, and of indefinitely varying the manufacture' (Bergson, 1960: 146).

It is here that I wish to turn to routines, as forms of sedimented practice. While much of the work on routines has been focused on performance, creativity and variation, I wish to suggest that this is to neglect the extent to which practices become sedimented and endure over time (Feldman 2000; Feldman and Pentland, 2003). The extent and nature of that endurance is an empirical matter, but I want to draw on the work of Luciana D'Adderio on the importance of Standard Operating Procedures in fixing routines. As she observes 
...formal procedures and rules can always - in theory - be worked around and dismissed, in practice they often play a role. Especially when embedded in artefacts such as software, and/or entangled into thick organisational interrelationships, they become visible, pervasive, difficult to change or avoid, easier to enforce (D'Adderio, 2008: 784).

These routines provide, I would suggest, the immediate objective structures that actors face when they pursue their personal projects. There may be degrees of flexibility in how the constraints that they provide are either perceived or navigated, but routines provide situational logics which condition action. In some cases they do so by providing what seems to be a natural course of action, so response becomes more a matter of instinct, of responses finely tuned to the cues given by a situation. In other cases those courses of action can be challenged, but only by paying the opportunity costs of so doing. What this suggests is that rather than retreat into a rather mystical intuitionism, Bergson's work might make us consider the relationship between the practical products of intelligence, manifested as routines and artefacts, and the instinctual action, action mediated by the capacity for reflection manifest in intuition.

\section{Conclusion}

Clearly, this discussion has only focused on a small part of Bergson's work seen through the lens of what is in turn a large body of work. However, the primary aim was to challenge the association of Bergson's work with a strong process theory. This has been done not by presenting a stark contrast between an ontology of flows and movement on the one hand and an ontology of static objects on the other, but rather by a suggestion that there are approaches which eschew such a Manichean division. In so doing, I have suggested that there are some points of agreement. If one drops notions of absolute truth in favour of what Whittington and Mayer (2000: 4) call 'a modestly generalizing social science of management', then we can agree that often an aesthetic response to our world can be more revealing. However, it is better to leave such efforts to those who have more aptitude for it; our challenge is to seek better understanding of the organizations which shape our lives. Strong 
process theorists give us little purchase on how this might be done. Indeed, some of their suggestions seem contradictory. We have seen this in the injunction to be introspective, a visual metaphor which contradicts the emphasis placed on the weakness of sight as a means of knowing. It also seems odd to couple the name of Foucault, who was concerned to problematize notions of enduring attributes of what it is to be human by providing contingently situated accounts of the conditions of possibility for forms of subjectivity, with a Bergsonian attachment to deep forms of the self. A similar comment could be made about yoking Bergson to Bourdieu (Chia and Holt, 2009; Nayak and Chia, 2011). For whatever we might say about the nature and constitution of habitus, its role in regulating practices is clearly social, in a way that enables us to trace regularities in social practice (Chia and Holt, 2006). Those regularities might emerge from habitual engagement with practice, but the regularities are collective products. This seems to sit uncomfortably with Bergson's focus on the duration of consciousness against the shadow practices of the social world. The problem here seems to be with generalizing from accounts which are focused on individual consciousness to the social. It is here that formulations from the tradition of critical realism which focus on, as Archer does, the articulation between interior subjective thoughts and the social might be more productive.

One way of doing this is by examining organizational practice, especially routines. Whilst one can accept that there can be subtle variations in routines every time they are performed, and that over time such variations might lead to changes in their character, routines are one way of recognising the relatively enduring sedimentation of process. The degree to which such routines endure is a matter of empirical investigation, but such investigation needs to be conditioned by an awareness of the ways in which practices sediment and crystallise flows. This is particularly the case when they are inscribed in artefacts, with information and communication technology systems being an important vehicle for such inscription. Once so inscribed, routines, the product of intellect, become powerful shaping forces for the exercise of intuition. One could argue, further, that they shape that very intuition by constraining the universe of available options. Such constraints can always be resisted 
but such resistance bears with it costs. In turn, these routines, borne by artefacts, are the aspects of broader structures that actors encounter directly. Those structures are in part the organizational structures which provide positions by virtue of which certain actors obtain the power to shape routines. However, what might be more significant and enduring are the broader structures of thought, what Foucault terms as discourses, which shape what it is possible to say or think at a particular time (Pearce and Woodiwiss, 2001). Practices, such as routines, are not simply patterns of repeated actions responding to functional needs, but are shaped by what is considered to be legitimate and appropriate in particular contexts. If we are take Bergson's injunctions seriously about the way that time is irreversible, so that the past is constantly penetrating the present, then we need to consider how the sedimented and enduring products of human activity condition and shape what is considered appropriate in the social world.

This raises some interesting questions about memory and history (Rowlinson, Hassard and, Decker 2015). While practices, such as organizational routines, are constantly being performed and so often subject to subtle changes, their parameters are often strongly conditioned by the past. It is here that 'strong' process theorists and others diverge. For the former, the focus is on memory and the uses of history, that is, on how actors in the present mobilize the past in order to act in the present. There is, of course, much of interest in such a focus, not least in the way that actors draw on selective representations of the past. This is especially the case when powerful actors control what is preserved and how it is presented through practices like corporate archives (Foster et al, 2011). However, as Bergson noted for the individual, history is not always that which actors remember but that which, even if not consciously accessible to present actors, continues to shape their actions. One thinks here of the work of Norbert Elias (2000) on what he termed the 'civilizing process'. Over large sweeps of time, he argued, new practices come into being, practices which from a later vantage point might seem mundane and obvious, like new forms of cutlery. Taken up initially in elite social groups, a process of emulation disseminates practices such as the use of the fork to eat food through society until it becomes taken for granted. With such practices come associated ideas of 
what constitutes civilised conduct, ideas which then themselves form the taken for granted backdrop for actions in the present.

The challenge, of course, is accessing and tracing the history of such processes. Without the direct access to practices that ethnographers can obtain, we are left with just the traces of such practices. For historians, however, the most valuable documents are those which were produced as an integral part of activities, with no thought as to their ultimate preservation (Lipartito, 2014). Such documents can be a valuable check of the vagaries of memory. However, by themselves they are mute as to the meanings associated with practices such as organizational routines. Here, as process theorists suggest, literature is one valuable resource. The casual anti-Semitism of the English 'gentleman' in Ford Madox Ford's (2012) novel of the First World War, Parade's End, is a minor and passing feature of his work, but it is perhaps all the more revealing for that. It suggests some of the mentalities that lay behind the construction of a particularly British view of management, one with a strong focus on leadership and character over technical expertise (Mutch, 2006). In some particularly fortunate cases we have the survival of diaries, especially those kept with no view to eventual publication, which can give access to contemporaneous casts of mind. Combined with a view to examining processes, the practices of the historian can help trace how they come to be solidified in practices such as routines.

This distinction between memory and history speaks to a larger concern with process theory, mirroring as it does the distinction between 'building' and 'dwelling' in organizational strategy promulgated by Chia and Holt. This draws on more sources than Bergson, but Bergson figures prominently in the suggestion that we focus more on how strategy is an emergent process best developed through a rich absorption in the moment, 'where detached seeing and contemplation give way to a locally sensitive, immersed, guileful and opportunistic form of doing' (Chia and Holt, 143). What the discussion of Bergson at least might suggest is that this is a one-sided view of one particular process theorist. We need both building and dwelling, both memory and history, if we are 
to give an adequate account of organizational practices. However, this discussion of Bergson is not just an opportunity to point to some weaknesses in the project of 'strong' process thinking. It is also to suggest that those influenced by critical realist perspectives, who have tended to place their emphasis on the structural constraints on action, might do well to attend to practices, such as organizational routines. It is because this is where organizational actors encounter the situational logics that the broader factors supply, even if this logic is not immediately obvious. Critical realism is an approach that is inherently processual and historical (Mutch, 2014) and as such ought to offer much more than the static and reified accounts that caricatured representations of it suggest.

References

Archer, Margaret. (1995) Realist Social Theory: The Morphogenetic Approach, Cambridge: Cambridge University Press.

Archer, Margaret. (2000) Being Human: The Problem of Agency, Cambridge: Cambridge University Press.

Archer, Margaret. (2003) Structure, Agency and the Internal Conversation, Cambridge: Cambridge University Press.

Bakken, Tore and Hennes, Tor, (2006) 'Organizing is Both a Verb and a Noun: Weick Meets Whitehead', Organization Studies, 27(11) 1599-1616.

Barad, Karen (2007) Meeting the Universe Halfway: Quantum Physics and the Entanglement of Matter and Meaning, Durham NC: Duke University Press.

Bergson, Henri (1910) Time and Free Will: An Essay on the Immediate Data of Consciousness, London: George Allen \& Unwin.

Bergson, Henri (1960) Creative Evolution, London: Macmillan 1911. 
Bergson, Henri (2007) Matter and Memory, New York: Cosimo 1912.

Beyes, Timon and Steyaert, Chris (2011) 'Spacing Organization: Non-Representational Theory and Performing Organizational Space', Organization, 19(1) 45-61.

Bhaskar, Roy (1982) 'Emergence, Explanation and Emancipation', in Paul Secord (ed) Explaining Human Behavior, Beverley Hills: Sage 275-310.

Bhaskar, Roy (1994) Plato etc.: The Problems of Philosophy and their Resolution, London: Verso.

Borch, Christian (2009) 'Organizational Atmospheres: Foam, Affect and Architecture', Organization, 17(2) 223-241.

Brown, Stephen (2006) 'Bonga, Tromba and the Organizational Impetus: Evolution and Vitalism in Bergson', Culture and Organization, 12(4) 307-319.

Calori, Roland (2002) 'Organizational Development and the Ontology of Creative Dialectical Evolution', Organization, 9(1) 127-150.

Chia, Robert (1997) 'Essai : Thirty Years On: From Organizational Structures to the Organization of Thought', Organization Studies, 18(4) 685-707.

Chia, Robert (1998) 'From Complexity Science To Complex Thinking: Organization As Simple Location', Organization, 5(3) 341-369.

Chia, Robert and Holt, Robin (2006) 'Strategy as Practical Coping: A Heideggarian Perspective', Organization Studies, 27(5) 635-655. 
Chia, Robert and Holt, Robin (2009) Strategy without Design: The Silent Efficacy of Indirect Action, Cambridge: Cambridge University Press.

Contu, Alesia and Willmott, Hugh (2005) 'You Spin Me Round: The Realist Turn in Organization and Management Studies', Journal of Management Studies, 42(8) 1645-1662.

Cunliffe, Ann, Luhman, John, and Boje, David (2004) 'Narrative Temporality: Implications for Organizational Research', Organization Studies, 25(2) 261-286.

D'Adderio, Luciana (2008) 'The Performativity of Routines: Theorising The Influence of Artefacts and Distributed Agencies on Routines Dynamics', Research Policy, 37 769-789.

Damasio, Anthony (1994) Descartes Error : Emotion, Reason and the Human Brain, London: Picador.

Elias, Norbert (2000) The Civilizing Process: Sociogenetic and Psychogenetic Investigations, Oxford: Blackwell.

Feldman, M. (2000) Organizational routines as a source of continuous change, Organization Science, 11(6), 611-629.

Feldman, M. and Pentland, B, (2003) Reconceptualizing organizational routines as a source of flexibility and change, Administrative Science Quarterly, 48, 94-118.

Ford, Ford Madox (2012 [1924-1928]) Parade's End, London: Penguin.

Foster, William, Suddaby, Roy, Minkus, Alison and Wiebe, Elden (2011) 'History as social memory assets: The example of Tim Hortons', Management \& Organizational History, 6(1), 101-120. 
Ghosh, Peter (2008) A Historian reads Max Weber: Essays on the Protestant Ethic, Wiesbaden: Harrassowitz Verlag.

Hassard, John and Cox, Julie (2013) 'Can Sociological Paradigms Still Inform Organizational Analysis? A Paradigm Model for PostParadigm Times.', Organization Studies, 34(11) 17011728.

Helin, Jenny, Hennes,Tor, Hjorth Daniel and Robin Holt (2014) The Oxford Handbook of Process Philosophy and Organisation Studies, Oxford: Oxford University Press.

Hennes, Tor and Bakken, Tore (2003) 'Implications of Self-Reference: Niklas Luhmann's Autopoiesis and Organization Theory', Organization Studies, 24(9) 1511-1535.

Kavanagh, Donncha (2004) 'Ocularcentrism and its Others: A Framework for Metatheoretical Analysis', Organization Studies, 25(3) 445-464.

Korczynski, Marek (2011) 'The Dialectical Sense of Humour: Routine Joking in a Taylorized Factory', Organization Studies, 32(10) 1421-1439.

Linstead, Stephen and Thanem, Torkild (2007) 'Multiplicity, Virtuality and Organization:The Contribution of Gilles Deleuze', Organization Studies, 28(10) 1483-1501.

Linstead, Stephen (2014) 'Henri Bergson (1859-1941)' in Helin et al (eds) The Oxford Handbook of Process Philosophy and Organisation Studies, Oxford: Oxford University Press 218-235.

Lipartito, Kenneth (2014) 'Historical Sources and Data' in Marcelo Bucheli and R. Daniel Wadhwani, Organizations in Time: History, Theory, Methods, Oxford: Oxford University Press, 284-304. 
Meyer, Renate and Boxenbaum, Eva (2010) 'Exploring European-ness in Organization Research', Organization Studies, 31(6) 737-755.

Moll, Ian (2004) 'Psychology, Biology and Social Relations', Journal of Critical Realism, 3(1) 49-76.

Mutch, Alistair (2006) 'The institutional shaping of management: in the tracks of English individualism', Management \& Organization History, 1(3), 251-271.

Mutch, Alistair (2014) 'History and documents in critical realism', in Edwards, P., O'Mahoney, J. and Vincent, S. (eds) Studying Organizations Using Critical Realism: A Practical Guide, Oxford: Oxford University Press, 2014, 223-240.

Nayak, Ajit (2008) 'On the Way to Theory: A Processual Approach', Organization Studies, 29(2) 173-190.

Nayak, Ajit and Chia, Robert (2011) 'Thinking Becoming and Emergence: Process Philosophy and Organization Studies', Research in the Sociology of Organizations, 32, 281-309.

Norris, Christopher (2000) Quantum Theory and the Flight from Realism: Philosophical Responses to Quantum Mechanics, London: Routledge.

O'Doherty, Damian (2007) 'The Question of Theoretical Excess: Folly and Fall in Theorizing Organization', Organization, 14(6) 837-867.

Painter-Morland, Mollie and Deslandes, Ghislain, (2014) 'Gender and visionary leadership: Rethinking 'vision' with Bergson, Deleuze and Guattari', Organization, 21(6) 844-866.

Pearce, Frank and Woodiwiss, Tony (2001) 'Reading Foucault as a Realist', in J. Lopez and G. Potter (Eds.) After Postmodernism, London: Athlone Press 51-62. 
Pentland, Brian, Feldman, Martha, Becker, Marcus and Peng, Liu, (2012) 'Dynamics of Organizational Routines: A Generative Model', Journal of Management Studies, 49(8) 14841508.

Reed, Mike (2005) 'Reflections on the 'Realist Turn' In Organization And Management Studies', Journal of Management Studies, 42(8) 1621-1644.

Rose, Steven (1993) The Making Of Memory: From Molecules To Mind, London: Bantam.

Rose, Hilary (1993) 'Rhetoric, Feminism and Scientific Knowledge or from Either/Or to Both/And', in Roberts and Good (eds), The Recovery of Rhetoric, London: Bristol Classical Press, 203-223.

Rowlinson, M, Hassard, J. and Decker, S. (2014) Research strategies for organizational history: a dialogue between historical theory and organization theory, Academy of Management Review, 39(3), 250-274.

Sayer, Andrew (1992) Method In Social Science: A Realist Approach, London: Routledge.

Schatzki, Theodore (2006) 'On Organizations as they Happen', Organization Studies, 27(12) 1863-1873.

Shotter, John (2006) 'Understanding Process From Within: An Argument for 'Withness'Thinking', Organization Studies, 27(4) 585-604.

Shotter, John (2008) 'Dialogism and Polyphony in Organizing Theorizing in Organization Studies: Action Guiding Anticipations and the Continuous Creation of Novelty', Organization Studies, 29(4) 501-524. 
Simpson, Barbara (2009) 'Pragmatism, Mead and the Practice Turn', Organization Studies, 30(12) 1329-1347.

Stones, Rob (2005) Structuration Theory, Basingstoke: Palgrave macmillan.

Thanem, Torkild (2006) 'Living on the Edge: Towards a Monstrous Organization Theory', Organization, 13(2) 163-193.

Tsoukas, Haridimos and Chia, Robert (2002) 'On Organizational Becoming: Rethinking Organizational Change', Organization Science, 13(5) 567-582.

Weber, Klaus and Glynn, Mary Ann (2006) 'Making Sense with Institutions: Context, Thought and Action in Karl Weick's Theory', Organization Studies, 27(11) 1639-1660.

Weik, Elke (2011) 'In Deep Waters: Process Theory between Scylla and Charybdis', Organization, 18(5) 655-672.

Westwood, Robert (2004) 'Comic Relief: Subversion and Catharsis in Organizational Comedic Theatre', Organization Studies, 25(5) 775-795.

Whittington, Richard and Mayer, Michael (2000) The European Corporation: Strategy, Structure and Social Science, Oxford: Oxford University Press.

Wood, Martin and Ferlie, Ewen (2003) 'Journeying from Hippocrates with Bergson and Deleuze', Organization Studies, 24(1) 47-68. 